Acta Crystallographica Section D

Biological

Crystallography

ISSN 0907-4449

P. T. Erskine, ${ }^{a}$ L. Coates, ${ }^{a} \neq$

R. Newbold, ${ }^{\text {b }}$ A. A. Brindley,

F. Stauffer, ${ }^{\text {c }}$ G. D. E. Beaven, ${ }^{\text {a }}$

R. Gill, ${ }^{\text {a }}$ A. Coker, ${ }^{\text {a }}$ S. P. Wood, ${ }^{\text {a }}$

M. J. Warren, ${ }^{b}$ P. M. ShoolinginJordan, ${ }^{\mathrm{a}} \mathrm{R}$. Neier ${ }^{\mathrm{c}}$ and

J. B. Cooper ${ }^{\mathrm{a} *}$

${ }^{a}$ School of Biological Sciences, University of Southampton, Bassett Crescent East, Southampton SO16 7PX, England, 'bSchool of Biological Sciences, Queen Mary, University of London, Mile End Road, London E1 4NS, England, and ' Institut de Chimie, Université de Neuchâtel, Avenue Bellevaux 51,

Case Postale 2, CH-2007 Neuchatel 7, Switzerland

₹ Current address: Neutron Diffraction Group, Los Alamos National Laboratory, New Mexico, USA.

Correspondence e-mail:

j.b.cooper@soton.ac.uk

\title{
Structure of yeast 5-aminolaevulinic acid dehydratase complexed with the inhibitor 5-hydroxylaevulinic acid
}

The X-ray structure of the enzyme 5-aminolaevulinic acid dehydratase (ALAD) from yeast complexed with the competitive inhibitor 5-hydroxylaevulinic acid has been determined at a resolution of $1.9 \AA$. The structure shows that the inhibitor is bound by a Schiff-base link to one of the invariant active-site lysine residues (Lys263). The inhibitor appears to bind in two well defined conformations and the interactions made by it suggest that it is a very close analogue of the substrate 5-aminolaevulinic acid (ALA).

\section{Introduction}

The enzyme 5-aminolaevulinic acid dehydratase (ALAD, also known as porphobilinogen synthase; EC 4.2.1.24) catalyses an early step in the biosynthesis of tetrapyrroles involving the condensation of two 5-aminolaevulinic acid (ALA) molecules to form the pyrrole porphobilinogen (PBG; see Fig. 1; Jordan, 1991, 1994; Warren \& Scott, 1990; Jaffe, 1995, 2003). Subsequent enzymes in the pathway cyclize four of these PBG molecules to make the core tetrapyrrole framework uroporphyrinogen III, which undergoes various modifications to form a variety of essential metallo-prosthetic groups, including haem, chlorophyll and the cobalamins. ALAD enzymes share a high degree of sequence identity, contain about 350 amino acids per subunit and are usually octameric. In humans, hereditary deficiencies in ALAD give rise to the rare disease Doss porphyria (Doss et al., 1979) and the exquisite sensitivity of the human enzyme to inhibition by lead ions is a major causative factor in acute lead poisoning (Simons, 1995; Warren et al., 1998).

The X-ray structures of ALADs from several species have been determined and several inhibitor complexes have been studied (Erskine, Senior, Awan et al., 1997; Erskine, Newbold et al., 1999, 2001; Erskine, Norton et al., 1999; Frankenberg et al., 1999; Mills-Davies, 2001; Erskine, Coates et al., 2001). In these structures, the enzyme is a homo-octamer with each

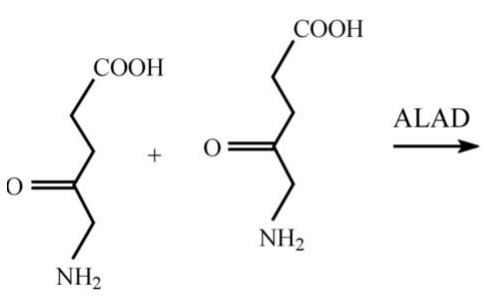

5-Aminolaevulinic acid

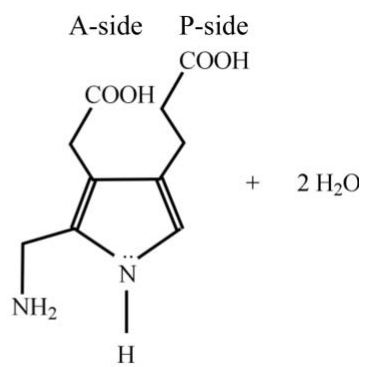

Porphobilinogen
Figure 1

The reaction catalysed by 5 -aminolaevulinic acid dehydratase (ALAD). Two molecules of 5-aminolaevulinic acid (ALA) are condensed to form the pyrrole porphobilinogen (PBG).
Received 21 July 2004

Accepted 13 June 2005

PDB Reference: 5-aminolaevulinic acid dehydratase, 1w31, r1w31sf. 
subunit adopting a $(\beta / \alpha)_{8}$ or TIM-barrel fold with an $\mathrm{N}$ terminal arm which in yeast ALAD is 39 residues in length (Fig. 2). Within the octamer, subunits form dimers in which each subunit has its $\mathrm{N}$-terminal arm wrapped around the barrel of the other monomer. The octamers result from sideby-side packing of the closely associated dimers, giving a quaternary structure in which all eight active sites are oriented towards the outer surface and are independent. The active site of each subunit is located in a pronounced cavity formed by loops at the C-terminal ends of the $\beta$-strands forming the TIM barrel. Recently, evidence has been found for hexameric quaternary forms of some ALADs (Breinig et al., 2003; Bollivar et al., 2004).

At the base of the active site are two lysine residues (210 and 263 in yeast ALAD), one of which (Lys263) is known to form a Schiff-base link to the first molecule of substrate that binds to the active site (Jordan \& Gibbs, 1985; Gibbs \& Jordan, 1986). Single-turnover experiments with labelled ALA have shown that the substrate bound to Lys 263 is incorporated into the propionic acid side, or P-side, of the product $\mathrm{PBG}$, whereas the second substrate molecule forms the acetic acid side, or A-side, of PBG (see Fig. 1). Thus, catalysis was shown to proceed by formation of a Schiff-base link at the P-site between the 4-keto group of substrate ALA and an invariant lysine residue, equivalent to Lys263 in yeast ALAD.

Recently, the structures of several ALADs complexed with the inhibitors 4,7-dioxosebacic acid and 5-fluorolaevulinic have been solved at high resolution (Erskine, Coates et al., 2001; Kervinen et al., 2001; Frère et al., 2002). Intriguingly, these inhibitors form two Schiff bases at the active site involving Lys210 as well as Lys263 in yeast ALAD numbering.
Table 1

Statistics for entire data set.

\begin{tabular}{ll}
\hline Resolution range $(\AA)$ & $44.3-1.9(2.0-1.9)$ \\
$R_{\text {merge }}(\%)$ & $5.8(41.9)$ \\
Completeness $(\%)$ & $100.0(100.0)$ \\
Multiplicity & $11.9(10.0)$ \\
Mean $I / \sigma(I)$ & $24.1(6.1)$ \\
Fraction $I>3 \sigma(I)(\%)$ & 84.1 \\
Refinement & \\
$R$ factor $(\%)$ & 18.95 \\
$R_{\text {free }}(\%)$ & 24.93 \\
No. of reflections & 35723 \\
R.m.s.d.s $(\AA)$ & \\
Bond lengths & 0.004 \\
1-3 distances & 0.012 \\
Bumps & 0.031 \\
Chiral tetrahedra & 0.007 \\
Main-chain planes & 0.012 \\
Side-chain planes & 0.009 \\
\hline
\end{tabular}

The structural evidence that both invariant lysines form Schiff bases with some inhibitors suggests that catalysis involves a double Schiff-base mechanism.

In many ALADs, an active-site zinc ion has been implicated in the catalytic mechanism and is thought to act on substrate bound to the A-site. The zinc-binding site is formed by the following residues in yeast ALAD: Cys133, Cys135 and Cys143. In contrast, plant and some bacterial ALADs require magnesium and lack the triple-cysteine sequence motif, which is replaced by other amino acids (predominantly aspartate residues) that were thought likely to coordinate an active-site magnesium ion (Boese et al., 1991). However, no electron density for an active-site magnesium has been found in crystal structures of several of these ALADs (Frankenberg et al., 1999; Coates et al., 2004) and there is evidence that the enzyme

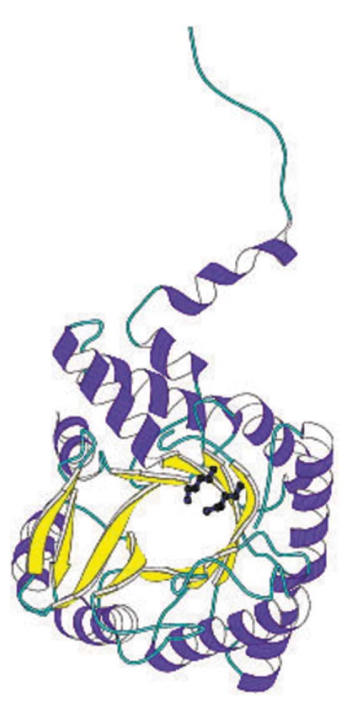

(a)

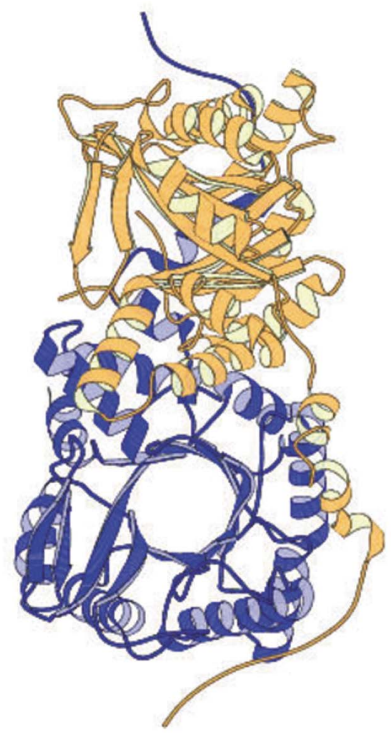

(b)

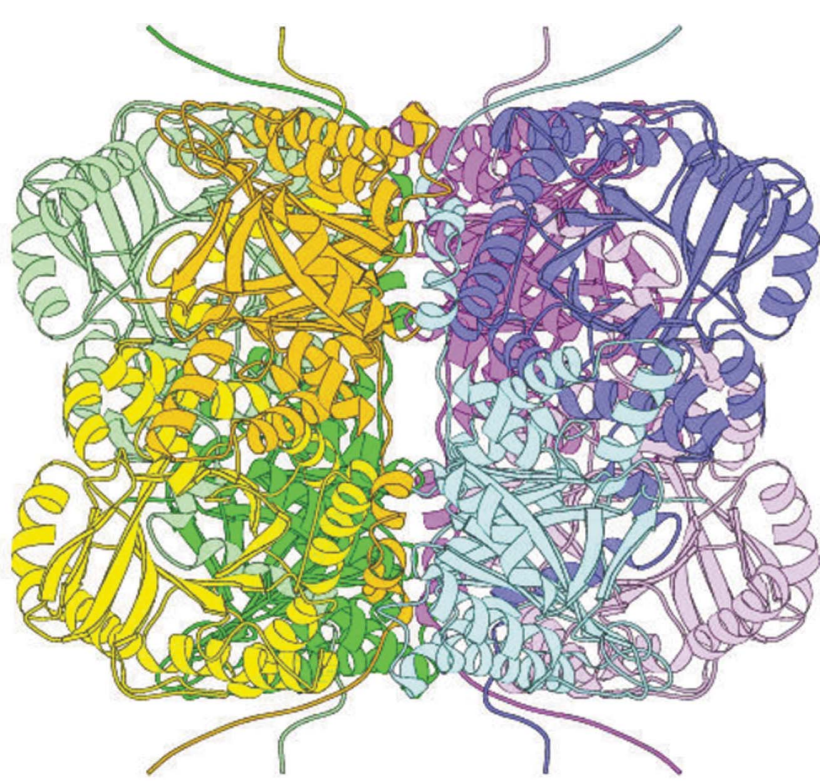

(c)

Figure 2

(a) A ribbon diagram of the TIM-barrel fold of the ALAD monomer with its pronounced N-terminal arm and two active-site lysines shown in ball-andstick representation. $(b)$ The assembly of ALAD monomers (coloured differently) to form dimers and $(c)$ the organization of the functional ALAD octamer. This figure and others similar were prepared using the programs MOLSCRIPT (Kraulis, 1991) and BOBSCRIPT (Esnouf, 1997). 
from some species is completely metal-independent (Bollivar et al., 2004). Thus, it is likely that any apparent magnesium dependence probably arises from the enzyme's allosteric metal-binding site at the subunit interface, which was first characterized in the Escherichia coli enzyme (Erskine, Norton et al., 1999). A more detailed description of the metal requirement of ALADs is given in Jaffe (2003).

We have analysed the structures of ALADs in which the active site is occupied by various inhibitors and all were found to form a Schiff base with Lys263 (Erskine, Newbold et al., 2001). In addition, the structure of substrate (ALA) bound in this site has been determined (Erskine, Newbold et al., 2001). The structure of this complex was obtained by crystallizing partially purified yeast ALAD and ALA was found to be covalently bound as a Schiff base to Lys263 at the P-site. The structure of a putative intermediate resembling covalently bound product has also been determined by co-crystallizing the yeast enzyme in the presence of added substrate ALA (Erskine et al., 2003). We now report on the high-resolution $\mathrm{X}$-ray structure of the inhibitor 5-hydroxylaevulinic acid (Fig. 3), which is a close analogue of the substrate ALA, bound to the yeast ALAD enzyme.

\section{Materials and methods}

Recombinant yeast ALAD was expressed and purified as described previously (Senior et al., 1996; Erskine, Senior, Awan et al., 1997). Crystals of yeast ALAD with 5-hydroxylaevulinic acid bound were obtained by co-crystallizing the enzyme in the presence of the inhibitor. The hanging-drop vapour-diffusion method was used with 5-hydroxylaevulinic acid present at a concentration of $10 \mathrm{~m} M$ and enzyme present at a concentration of $2 \mathrm{mg} \mathrm{ml}^{-1}$. Apart from the presence of inhibitor, the crystallization conditions (2-10\% PEG 6000, $200 \mathrm{~m} M$ Tris- $\mathrm{HCl} \mathrm{pH}$ range 7.0-8.0, $6 \mathrm{~m} M \beta$-mercaptoethanol and $70 \mu M$ zinc sulfate) are otherwise identical with those used to crystallize the native enzyme (Erskine, Senior, Maignan et al., 1997). Crystals of the complex, which appeared within 3-4 weeks, belong to space group I422, with unit-cell parameters $a=b=102.6, c=168.4 \AA$. The crystals were flashcooled in liquid ethane and X-ray data were collected at ESRF (Grenoble) using the ID29 beamline with the crystal maintained at a temperature of $100 \mathrm{~K}$ using an Oxford Cryosystems cooler. The data were processed using MOSFLM (Leslie, 1992) and the CCP4 suite (Collaborative Computational Project, Number 4, 1994). The structure was refined using

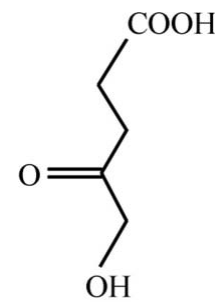

Figure 3

The chemical formula of the ALAD inhibitor 5-hydroxylaevulinic acid.
SHELX (Sheldrick \& Schneider, 1997) and the program RESTRAIN (Haneef et al., 1985) was used for refinement of translation-libration-screw (TLS) tensors. Graphical rebuilding was performed using TURBO-FRODO (BioGraphics, Marseille, France) running on Silicon Graphics (SGI) computers.

\section{Results and discussion}

5-Hydroxylaevulinic acid (Fig. 3) is a competitive inhibitor of ALAD enzymes, typically with $K_{\mathrm{i}}$ values of $0.25 \mathrm{~m} M$ (Neier, 1997). The initial difference map for yeast ALAD co-crystallized with 5-hydroxylaevulinic acid showed convincing electron density for the inhibitor bound as a Schiff-base complex with one of the invariant active-site lysines (Lys263) in the P-site of the enzyme. The ligand was built into the density accordingly and the structure of the complex refined for several cycles after each round of manual rebuilding. The final electron-density map at a resolution of $1.9 \AA$ is shown in Fig. 4(a), where it can be seen that the inhibitor adopts two conformations on binding to the enzyme. This interpretation was partly based on the finding that most inhibitor complexes of yeast ALAD analysed previously at high resolution were found to exhibit similar disorder in the bound conformation of the inhibitor itself and the side chain of Lys 263 to which the inhibitors are attached (Erskine, Newbold et al., 2001). Evidence for the occurrence of two conformations was provided by refining the structure with the inhibitor built in one conformer alone, which yielded strong positive difference density for the other conformer (see Fig. $4 b$ ). Refinement of the occupancy of the two conformers yielded values of 52 and $48 \%$, suggesting that the inhibitor binds with equal preference for both of the conformations. The atoms of the bound inhibitor have a mean isotropic $B$ factor of $44.9 \AA^{2}$, which is comparable with the $B$ factors of the entire complex (mean $B_{\text {iso }}=49.27 \AA^{2}$ ), confirming that the inhibitor has bound to the majority of the enzyme molecules forming the crystal. This presumably reflects the buried state of the inhibitor, which is covered by the enzyme's active-site flap (residues 215-235). These $B$ factors appear to be rather high for a structure refined at $1.9 \AA$ resolution and we presume that this is an effect of the TLS refinement, since lower values were obtained when the structure was refined by conventional means only, e.g. the mean $B_{\text {iso }}$ for the complex was $39.6 \AA^{2}$, a value which is closer to the Wilson plot $B$ factor of $33.5 \AA^{2}$.

The electron density for the inhibitor is good except for the C-2 position: an effect common to other P-site ligands which exhibit disordered binding, e.g. the substrate ALA and laevulinic acid (Erskine, Newbold et al., 1999, 2001; Erskine, Coates et al., 2001). The electron density for the amino acids surrounding the inhibitor in the P-site is very good. In contrast, a number of the amino-acid side chains making up the unoccupied A-site have much poorer electron density. However, it has been shown that these become dramatically more ordered in the presence of inhibitors which occupy the A-site, e.g. 4,7-dioxosebacic acid (Erskine, Coates et al., 2001). 
The final structure, which was refined using data between 44.3 and $1.9 \AA$, has an $R$ factor of $18.95 \%$ and an $R_{\text {free }}$ of $24.93 \%$ (see Table 1). Refinement of the TLS tensors for the TIM-barrel and arm domains gave a significant improvement in $R_{\text {free }}$ of over $8 \%$. The final structure has $89.7 \%$ of its residues within the 'most favoured' regions of the Ramachandran plot by the PROCHECK criteria (Laskowski et al., 1993) and $9.6 \%$ of residues within the so-called 'additional allowed' boundary. No residues are in the disallowed regions. The temperature factors are reasonable except for a few residues in the active-site flap (most notably 228-230), where the electron density remains poor despite extensive efforts to rebuild these residues throughout the refinement process. Nonetheless, the electron density for the active-site loop in this complex is substantially better than that of the native enzyme.

The active site of ALAD is located in a large cavity at the $\mathrm{C}$-terminal end of the eight-stranded all-parallel $\beta$-barrel. It involves two invariant lysine residues (263 and 210 in yeast ALAD), as well as a zinc ion which is coordinated by three cysteine residues numbered 133, 135 and 143 in the yeast enzyme. The inhibitor in this study forms a Schiff base with Lys263 and is held in the P-site of the enzyme. The C-5 hydroxyl group of the inhibitor forms a strong hydrogen bond with the $-\mathrm{NH}_{2}$ side chain of the other invariant active-site lysine (Lys210) in one conformer. Whilst the inhibitor appears to bind in two conformations in the P-site, in both of these conformers the C-5 hydroxyl group interacts with the side chains of Asp131 and Ser179, which are strongly conserved and have been implicated in the mechanism by site-directed mutagenesis (Shoolingin-Jordan et al., 2002). The same interactions have been observed for the C-5 amino group of substrate ALA when bound to the P-site of the enzyme (Erskine, Newbold et al., 2001). The C-5 hydroxyl group also forms a hydrogen bond to the water molecule datively bound to the active-site zinc ion and the C-5 amino group of substrate ALA likewise also forms this interaction (Erskine, Newbold $e t$ al., 2001). The aliphatic parts of the inhibitor and substrate ALA (C-2 to C-5) reside in a hydrophobic pocket formed mainly by aromatic side chains of residues Phe89, Tyr216, Phe219, Tyr287 and Val289. Like ALA, the C-1 carboxyl group of hydroxylaevulinic acid forms hydrogen bonds with the side chains of Ser290 and Tyr329 in both of the bound conformers. Other hydrogen bonds are formed with the side chain of Tyr287 and the main-chain NH of Ser290 in one of the conformers only.

The A-site in this complex is a solvent-filled cavity bounded on one side by the P-site 5-hydroxylaevulinic acid molecule and on the other by two arginine residues (220 and 232) which are strongly conserved and are thought to interact with the

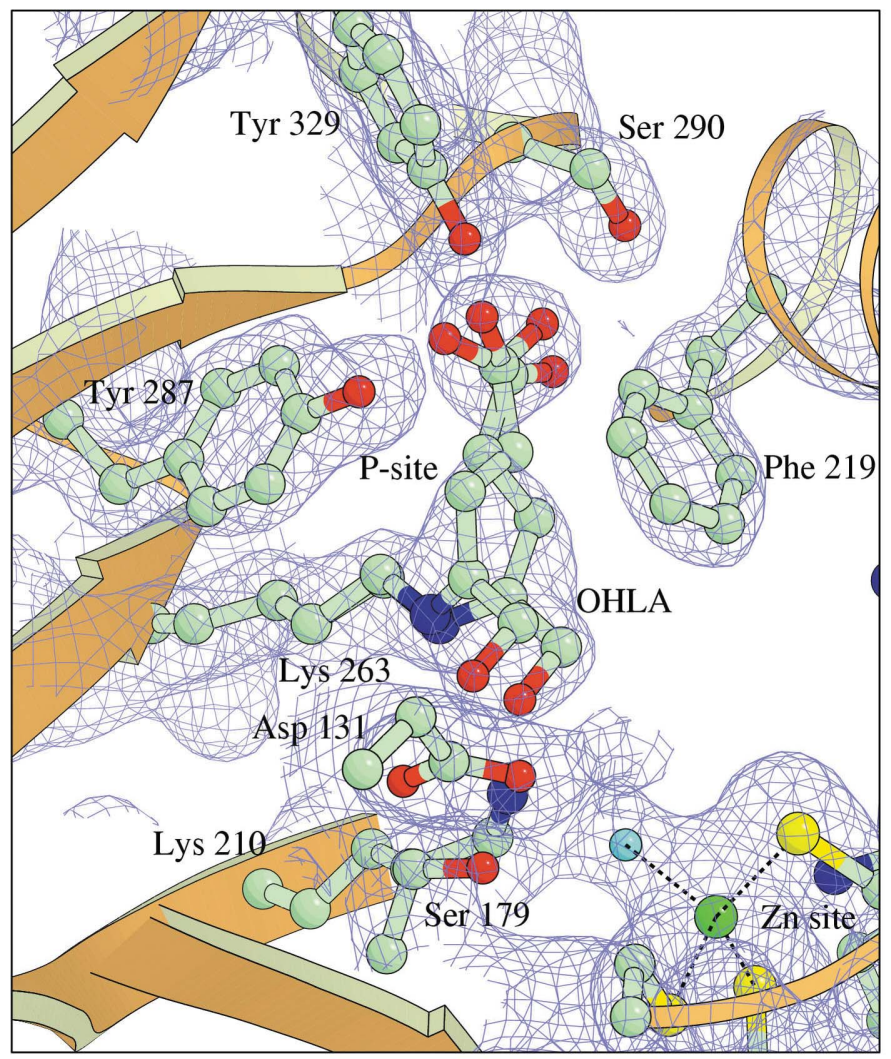

(a)

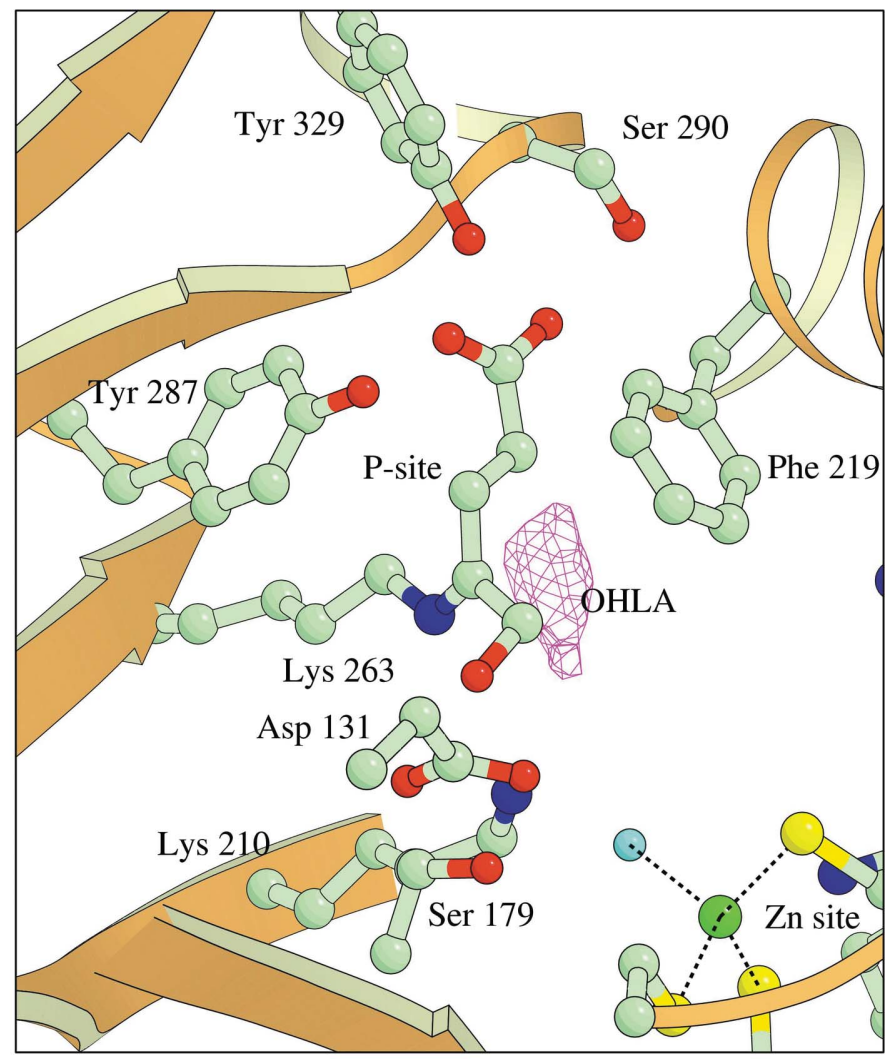

(b)

Figure 4

(a) The structure of the inhibitor 5-hydroxylaevulinic acid (labelled OHLA) bound in two conformations to one of the active-site lysines (Lys263) of yeast ALAD. The structure has been refined at $1.9 \AA$ resolution and the corresponding electron density, contoured at 1.0 r.m.s., is shown as purple lines. The active-site zinc ion is shown on the lower right. $(b)$ The same view of the bound inhibitor but showing only one conformation and the resulting positive difference density contoured at 4.5 r.m.s. (shown in magenta) indicating the presence of the other conformer. 
carboxyl of A-side substrate. Evidence for this was provided by bound structures of the inhibitors 4,7-dioxosebacic acid and 5-fluorolaevulinic acid, which occupy the A-site and P-site (Erskine, Coates et al., 2001; Kervinen et al., 2001; Frère et al., 2002). A major part of the A-site is formed by the zinc ion held by the side chains of three cysteines. As mentioned above, there is a solvent molecule bound to the zinc ion that is within hydrogen-bonding distance of the amino group of P-side ALA. It has been speculated that this solvent molecule may actually be a zinc-bound hydroxide which abstracts a proton from C-3 of A-side ALA as a prerequisite for formation of the $\mathrm{C}-\mathrm{C}$ bond between the two substrates (Erskine, Norton et al., 1999).

The current study shows that 5-hydroxylaevulinic acid appears in structural terms to be an exceptionally good analogue of the substrate ALA; both bind by making almost exactly the same interactions. The fact that the C-5 hydroxyl binds in the same position as the C-5 amino group of ALA suggests that the charge of the C-5 substituent does not have a great effect on its binding mode. The lower polarity of the hydroxylaevulinic acid compared with substrate ALA might also be expected to increase its bio-availability as an inhibitor of tetrapyrrole biosynthesis, possibly with in vivo applications.

We gratefully acknowledge the financial support of the Biotechnology and Biological Sciences Research Council (BBSRC, UK) and the European Synchrotron Radiation Facility (Grenoble, France) for beam time.

\section{References}

Boese, Q. F., Spano, A. J., Li, J. M. \& Timko, M. P. (1991). J. Biol. Chem. 266, 17060-17066.

Bollivar, D. W., Clauson, C., Lighthall, R., Forbes, S., Kokona, B., Fairman, R., Kundrat, L. \& Jaffe, E. K. (2004). BMC Biochem. 5, 17.

Breinig, S., Kervinen, J., Stith, L., Wasson, A. S., Fairman, R., Wlodawer, A., Zdanov, A. \& Jaffe, E. K. (2003). Nature Struct. Biol. 10, 757-763.

Coates, L., Beaven, G., Erskine, P. T., Beale, S. I., Avissar, Y. J., Gill, R., Mohammed, F., Wood, S. P., Shoolingin-Jordan, P. \& Cooper, J. B. (2004). J. Mol. Biol. 342, 563-570.

Collaborative Computational Project, Number 4 (1994). Acta Cryst. D50, 760-763.

Doss, M., Von-Tieperman, R., Schneider, J. \& Schmid, H. (1979). Klin. Wochenschr. 57, 1123-1127.

Erskine, P. T., Coates, L., Butler, D., Youell, J., Brindley, A. A., Wood, S. P., Warren, M. J., Shoolingin-Jordan, P. M. \& Cooper, J. B. (2003). Biochem. J. 373, 733-738.

Erskine, P. T., Coates, L., Newbold, R., Brindley, A. A., Stauffer, F., Wood, S. P., Warren, M. J., Cooper, J. B., Shoolingin-Jordan, P. M. \& Neier, R. (2001). FEBS Lett. 503, 196-200.
Erskine, P. T., Newbold, R., Brindley, A. A., Wood, S. P., ShoolinginJordan, P. M., Warren, M. J. \& Cooper, J. B. (2001). J. Mol. Biol. 312, 133-141.

Erskine, P. T., Newbold, R., Roper, J., Coker, A., Warren, M. J., Shoolingin-Jordan, P. M., Wood, S. P. \& Cooper, J. B. (1999). Protein Sci. 8, 1250-1256.

Erskine, P. T., Norton, E., Cooper, J. B., Lambert, R., Coker, A., Lewis, G., Spencer, P., Sarwar, M., Wood, S. P., Warren, M. J. \& Shoolingin-Jordan, M. J. (1999). Biochemistry, 38, 4266-4276.

Erskine, P. T., Senior, N., Awan, S., Lambert, R., Lewis, G., Tickle, I. J., Sarwar, M., Spencer, P., Thomas, P., Warren, M. J., ShoolinginJordan, P. M., Wood, S. P. \& Cooper, J. B. (1997). Nature Struct. Biol. 4, 1025-1031.

Erskine, P. T., Senior, N., Maignan, S., Cooper, J., Lambert, R., Lewis, G., Spencer, P., Awan, S., Warren, M., Tickle, I. J., Thomas, P., Wood, S. P. \& Shoolingin-Jordan, P. M. (1997). Protein Sci. 6, 17741776.

Esnouf, R. (1997). J. Mol. Graph. Model. 15, 132.

Frankenberg, N., Erskine, P. T., Cooper, J. B., Shoolingin-Jordan, P. M., Jahn, D. \& Heinz, D. W. (1999). J. Mol. Biol. 289, 591-602.

Frère, F., Schubert, W. D., Stauffer, F., Frankenberg, N., Neier, R., Jahn, D. \& Heinz, D. W. (2002). J. Mol. Biol. 320, 237-247.

Gibbs, P. N. B. \& Jordan, P. M. (1986). Biochem. J. 236, 447-451.

Haneef, I., Moss, D. S., Stanford, M. J. \& Borkakoti, N. (1985). Acta Cryst. A41, 426-433.

Jaffe, E. K. (1995). J. Bioenerg. Biomembr. 27, 169-179.

Jaffe, E. K. (2003). Chem. Biol. 10, 25-34.

Jordan, P. M. (1991). New Comprehensive Biochemistry, Vol. 19, edited by A. Neuberger \& L. L. N. Van Deenen, pp. 1-65. Amsterdam: Elsevier.

Jordan, P. M. (1994). Curr. Opin. Struct. Mol. Biol. 4, 902-911.

Jordan, P. M. \& Gibbs, P. N. B. (1985). Biochem. J. 227, 1015-1020.

Kervinen, J., Jaffe E. K., Stauffer, F., Neier, R., Wlodawer, A. \& Zdanov, A. (2001). Biochemistry, 40, 8227-8236.

Kraulis, P. (1991). J. Appl. Cryst. 24, 946-950.

Laskowski, R. A., MacArthur, M. W., Moss, D. S. \& Thornton, J. M. (1993). J. Appl. Cryst. 26, 283-291.

Leslie, A. G. W. (1992). Jnt CCP4/ESF-EAMCB Newsl. Protein Crystallogr. 26.

Mills-Davies, N. L. (2001). PhD thesis. University of Southampton, UK.

Neier, R. (1997). Electronic Conference on Heterocyclic Chemistry 96 (ECHET 96). http://www.ch.ic.ac.uk/ectoc/echet96/papers/112/ index.htm.

Senior, N., Thomas, P. G., Cooper, J. B., Wood, S. P., Erskine, P. T., Shoolingin-Jordan, P. M. \& Warren, M. J. (1996). Biochem. J. 320, 401-412.

Sheldrick, G. M. \& Schneider, T. R. (1997). Methods Enzymol. 277, 319-343.

Shoolingin-Jordan, P. M., Spencer, P., Sarwar, M., Erskine, P. T., Cheung, K. M., Cooper, J. B. \& Norton, E. B. (2002). Biochem. Soc. Trans. 30, 584-590.

Simons, T. J. B. (1995). Eur. J. Biochem. 234, 178-183.

Warren, M. J., Cooper, J. B., Wood, S. P. \& Shoolingin-Jordan, P. M. (1998). Trends Biochem. Sci. 23, 217-221.

Warren, M. J. \& Scott, A. I. (1990). Trends Biochem. Sci. 15, 486491. 